\title{
NOSTALGIA FOR CRISIS: REPRESENTING REVOLUTION IN NORTH AMERICAN POPULAR CULTURE
}

\author{
By Emily Truman
}

In contemporary North America we no longer have revolutions; instead we have nostalgia for revolution. Benjamin Arditi's Politics on the Edges of Liberalism argues that the continued presence of marginal radical politics in Western liberal democracies is evidence of our nostalgia for revolution and that we are mourning an ideal state of the past. I argue that another more widespread site of evidence for our nostalgia for revolution is the proliferation of popular artefacts branded with revolutionary iconography. As a symbol, revolution is omnipresent in North American culture. It is on our t-shirts, magazine covers, book jackets, advertising posters, and in our language and conversations describing new political realities and cultural contexts. We are collectors of revolutionary culture: we wear it, read it, buy it, and talk about it.

As Elsner and Cardinal argue in The Cultures of Collecting we collect things because they are the material embodiment of our more abstract systems of knowledge. Understanding the ways in which we classify our knowledge, through the things we collect, is an attempt to understand our social order and our social histories. This desire to understand our world is reflected in the central themes of collecting that are: "desire and nostalgia, saving and loss, the urge to erect a permanent and complete system against the destructiveness of time" (Elsner and Cardinal 1). Elsner and Cardinal argue that while the act of collecting can reinforce the status quo through the reproduction of social boundaries or categories, the act of collecting can also challenge the status quo if we shift our focus towards the boundaries of our regulative frameworks of knowledge, and what might exist beyond those boundaries (3). In this way, everyday practices of collecting have the ability to illuminate how "official collections", such as 
those housed in museums, are involved in the project of reinforcing "official norms" (Elsner and Cardinal 4). Misfit collections, like the revolutionary artefacts we find circulating in North American popular culture, invite discussion of the boundaries of public discourse - why is it that the concept of revolution remains central in the public imagination? What does revolution represent to us? The answer to these questions are tied up in the intriguing relationship between the concepts of crisis and nostalgia, terms which we use to make sense of revolution and what it represents in contemporary North American culture.

In our material culture we tend to celebrate revolution as a symbol of change rather than condemning it as a symbol of crisis. This is rather curious given the similarities shared between the concepts. The Oxford English Dictionary defines crisis as "a state of affairs in which a decisive change for better or worse is imminent...[especially] in times of difficulty, insecurity, and suspense in politics or commerce" $(O E D)$. Similarly, revolution is defined as "an instance of great chance or alteration in affairs...[especially] a complete overthrow of the established government..." $(O E D)$. Both are defined as moments of change characterized by uncertainty, and in addition, they share similar etymologies. In the fifteenth and sixteenth centuries they were terms used to explain scientific conditions (crisis in relation to the human body, and revolution in relation to celestial bodies), and then between the seventeenth and nineteenth centuries their meanings shifted towards descriptions of political conditions $(O E D)$. Given the similarities they share, it is curious then that while we tend to regard crisis as a negative state, the idea of revolution is increasingly regarded as a positive one. Increasingly, we use the idea of revolution to engage in discussion about our political realities in the modern liberal democracy. We use revolution as a symbol to talk about change. Here, crisis is positioned as a positive state that has the potential to bring about positive social change. 
This discussion about change through crisis takes place through a material culture of revolution defined by the presence of "revolutionary goods". These goods invoke messages of change through the use of symbols from past revolutionary movements. Here, symbols of crisis denoting potential danger are transformed into symbols of change denoting potential social stability. The material culture of revolution that I am describing has a dominant aesthetic mode in North American popular culture; it tends to be communicated through nostalgia. Nostalgia attaches itself to material objects in ways that are visually identifiable, employing styles and symbols that are indicative of another historical time and place. Revolutionary goods take subjects from our current cultural context and present them through the lens of previously existing revolutionary symbols. This projection into the past is an attempt to contextualize the present - what a current symbol means is constructed in relation to the history of revolutionary iconography. There are two levels of analysis here: the object as presented through a nostalgic lens, and the subject as communicated through the use of a revolutionary symbol. Revolutionary goods then, are made up of two parts: the subject and object, which together serve the purpose of comforting us in our discussions of social change.

Here, with the idea of “comfort” I am borrowing from Marita Sturken's notion of "comfort culture". Sturken addresses the relationship between social history and the act of collecting in Tourists of History, a book exploring the rise of the material culture of comfort goods that constitutes an industry surrounding national traumatic events such as $9 / 11$ or the Oklahoma City bombing. These "comfort goods" are depoliticized artefacts such as snow globes and teddy bears that commemorate these national traumatic events and are sold at their sites as souvenirs. In addition to commemorating specific events however, comfort goods also allow American citizens to safely participate in political debates from afar because they are detached 
from the complicated political contexts that surround those events. I argue that revolutionary artefacts serve the same purpose in North American culture; these branded goods evoke a sentimental response to perceived "successful revolutions" of the past (such as the French Revolution, the Cuban Revolution, or the Feminist Movement in North America) and result in an idealizing of the past. Collecting, experiencing, and communicating through material culture performs a specific function - it allows citizens to participate in national events through a material culture of the everyday. Unlike Sturken however, who sees the consumption of "comfort culture" as a sign that Americans are becoming detached from their own political reality, I argue here that revolutionary nostalgia should be read as an engagement with the present and an indication of the desire to imagine the political future. Our nostalgia for revolution is an expression of political participation at the level of the everyday through the things we collect and through the symbols we use to communicate meaning.

Traditionally, the concept of nostalgia has been used to describe the condition of homesickness, or a sentimental longing for the familiar. Linda Hutcheon argues that despite the familiar Greek roots of the term nostalgia, the term has had a relatively short life, coming into popular use after 1688 when a medical student applied the term to the description of Swiss mercenaries who were physically ill over their longing to return home (par. 7). It is only in the nineteenth century that the meaning of the concept begins to shift towards the common definition that we understand today - nostalgia as a psychological condition rather than a physical one. Hutcheon argues that this shift in meaning was a move away from the idea of the spatial towards the idea of the temporal (par. 8); being afflicted with nostalgia then, or feeling nostalgic, indicates a search for lost time that is inaccessible but which we continually try to revive or retrieve. 
As a noun, nostalgia refers to the condition of being homesick or having a sentimental longing for the past. The term nostalgia, however, is also used as an adjective to describe a particular quality attached to subject or object. In relation to the project described here involving "revolutionary goods", nostalgia is positioned as the dominant aesthetic mode through which we talk about revolution in North American popular culture. Conceptualizing nostalgia as an aesthetic mode is not a new idea: in 1994 Toby Young and Tom Vanderbilt announced in the popular British magazine The Modern Review the end of irony as our central aesthetic mode of communication. Irony is no longer central because it has been striped of meaning due to its ubiquity in popular culture; Young and Vanderbilt argue instead that the new mode is nostalgia. They explain that the reason we need nostalgia is because culture, like technology and consumer goods, is produced according to the rule of planned obsolescence. Therefore, nostalgia tells us what products, trends, or histories we should be longing to return to (Young and Vanderbilt 6). While this conceptualization of nostalgia as a culturally dominant mode of expression is highly useful in relation to the overall project described in this paper, I disagree with Young and Vanderbilt's lamentation that the use of nostalgia to sell culture results in the favouring of mediated memories over actual events (7). In the case of "revolutionary nostalgia", we are not engaged in lamenting or sentimentalizing past events (mediated or actual); instead I argue that we are in fact looking towards the political future.

Nostalgia has generally been conceptualized as a sense of mourning for a past state, which means that, by definition, nostalgia does not allow for movement forward in time. This view has been examined in detail by Svetlana Boym and Dylan Trigg. However, more recently, Pickering and Keightley have argued for a re-conceptualization which acknowledges that nostalgia has multiple modes, and thus is open to multiple interpretations. Reconfiguring the 
concept of nostalgia involves moving away from the idea of nostalgia as oriented to the past, and towards an understanding of nostalgia as interacting with the past (Pickering and Keightley 929). For Pickering and Keightley, nostalgia is not a literal desire to return to the past, but a metaphorical desire to use the past as a model for the future (921). Figured as such, nostalgia becomes a useful conceptual framework through which to examine the meaning of revolution in North American popular culture because both concepts look to the past, but can also speak to our visions of the future.

A "comfort culture" of revolution then, is indicative of our nostalgia for crisis, but a very particular form of crisis. While we continue to formally theorize revolution as a mode of crisis that generates conditions of potential danger and uncertainty, in the popular imagination we interact with this idea in a different way. Revolution has become a sign or marker of potential social change. We navigate this mode of crisis using "revolutionary goods" which act as material sources of comfort. These goods fall into three categories: clothing, collectibles and media texts. While each category communicates "revolutionary nostalgia" in slightly different ways, they all share the same subject: the iconography of past revolutionary symbols.

Consider the following three symbols: Che Guevara, Chairman Mao, and Rosie the Riveter. All three of these symbols generate revolutionary kitsch in their own cultures (kitsch here being sentimentalized art or artefacts celebrating the subject): Che in Cuba, Mao in China, and Rosie in the United States. As well, the images of all three circulate in North American culture - both on material goods and in the media. Their meanings are not fixed: they fluctuate according to context. It is, however, fair to say that each symbol has come to represent a generalized sentiment in pop culture: for example Che is seen as a representation of "rebellion", "anti-establishment thinking", or perhaps more generally the notion of "change". Mao can be 
seen to represent "oppression", or more generally "conformity". And Rosie is made to stand in as a symbol of feminism, or more generally, the notion of "equality".

Whether worn, collected, or communicated in earnest, as is Che when positioned as the model hero, or with a sense of irony, as is Mao when positioned as the oppressive leader, revolutionary symbols continue to be employed with a nostalgic lens to the past - but we are using them to describe the present. It is also my contention that we are mobilizing a very specific form of nostalgia here - not just one which laments what once was (whether real or imaginary), but a sense of nostalgia that is oriented towards the future. This mobilization is taking place in various forms as previously mentioned - through clothing such as popular tshirts; collectibles such as kitschy colouring books, finger puppets, and bobble-heads; and media texts such as popular magazines and book covers. In many cases, these revolutionary goods reference nostalgia as a return to childhood innocence, by extension emphasizing revolution as playful subject matter, and literally transforming the subject into a toy to be played with.

At the level of object, this is a semiotic analysis of the symbols of revolution; at the level of subject, it is also an examination of the cultural contexts that surround the creation, dissemination, and use of revolutionary goods. Cultural context is highly significant because it informs and instructs our reading of revolution as a positive, rather than negative, social condition. Revolutionary goods are engaged in a process of intentional communication, which reflects not only their position as commodified objects, but also their role as historical subjects in present North American popular culture. Consider for example a button featuring the iconic image of "Rosie the Riveter" (yellow background, female figure dressed in blue, turned to the side, arm flexed); now imagine the face of "Rosie" replaced by that of Hillary Clinton. There is certainly an overlapping of feminist symbols that creates a richer meaning. However, consider 
how the meaning of this object shifts again when it is dropped into the context of the 2007 Democratic Party presidential candidate race in which Clinton ran. Suddenly the "We can do it" issuing forth from Clinton's mouth is not about abstracts, but about the specific way that change can be achieved: casting a vote for Clinton in this context is not just a movement to elevate her to the position of American President, but also infers that the act of doing this will further the cause of the feminist movement. Revolutionary goods mobilizing the concept of revolutionary nostalgia highlight the importance of context when considering how, when, and where mediated messages are communicated to audiences, readers and viewers. When we play with images of Rosie the Riveter now in relation to the political image of Hillary Clinton it is not because we want to return to the social and political conditions of nineteen-forties and -fifties North America, but because we want to access the symbolic value that Rosie represents as the embodiment of more abstract notions of change and equality.

Popular revolutionary artefacts represent more than our willingness to buy commodified counterculture, as Heath and Potter argue in The Rebel Sell. These artefacts, or collections of revolutionary culture, are more accurately an attempt to understand our own systems of knowledge - or more specifically, our present social system. The phenomenon of revolutionary goods suggests that under certain circumstances we conceive of crisis as a positive condition linked to the possibility of positive social change. The concept of revolutionary nostalgia then has the potential to broaden the ways in which we think about and approach the idea of social change in North American culture.

$\underline{\text { Works Cited }}$ 
Arditi, Benjamin. Politics on the Edges of Liberalism: difference, populism, revolution, agitation. Edinburgh: Edinburgh University Press, 2007.

Boym, Svetlana. The Future of Nostalgia. New York: Basic Books, 2001.

Elsner, John, and Roger Cardinal, eds. The Cultures of Collecting. Cambridge, MA: Harvard University Press, 1994.

Hutcheon, Linda. "Irony, Nostalgia and the Postmodern". University of Toronto English Library on-line (Ian Lancashire, Director), 1998. 24 Sept. 2008 $<\underline{\text { http://www.library.utoronto.ca/utel/criticism/hutchinp.html }>\text {. }}$

Oxford English Dictionary. $2^{\text {nd }}$ ed. New York: Oxford University Press, 1989. 24 Sept. 2008 $<\underline{\text { http://catalogue.library.carleton.ca/search } \sim \mathrm{S} 5 \text { ?/toxford+english+dictionary/toxford+engl }}$ ish+dictionary $/ 1 \% 2 \mathrm{C} 3 \% 2 \mathrm{C} 10 \% 2 \mathrm{CB} /$ eresource $\& \mathrm{FF}=$ toxford+english+dictionary+online $\& 1 \% 2 \mathrm{C} 1 \% 2 \mathrm{C} /$ indexsort $=->$.

Pickering, Michael, and Emily Keightley. "The Modalities of Nostalgia." Current Sociology 54 (2006): 919.

Potter, Andrew, and Joseph Heath. The Rebel Sell: Why the culture can't be jammed. Toronto: Harper Collins, 2003.

Sturken, Marita. Tourists of History: memory, kitsch and consumerism from Oklahoma City to Ground Zero. Durham: Duke University Press, 2007

Trigg, Dylan. The Aesthetics of Decay: Nothingness, Nostalgia and the Absence of Reason. New York: Peter Lang, 2006.

Young, Toby, and Tom Vanderbilt. (1994). “The End of Irony?” The Modern Review 1,14 (1994): 6-7. 